\title{
Letter to the Editor: Myelodysplastic Syndrome and Secondary Acute Leukemia After Treatment of Essential Thrombocythemia With Hydroxyurea
}

We have read with interest the report of Toh et al. [1] on acute leukemia following treatment of polycythemia vera and essential thrombocythemia (ET) with uracil mustard. One of their 16 ET patients treated by uracil mustard developed acute leukemia. The natural evolution of ET into leukemia is a rare event, which may be accelerated by the use of alkylating agents or ${ }^{32} \mathrm{P}$ therapy. Sedlacek et al. [2] and Gris et al. [3] recommend hydroxyurea as a relatively safe treatment modality for patients with ET.

However, one of our patients with ET developed acute leukemia following treatment with hydroxyurea. A 45year-old woman who underwent in 1968 a nephrectomy after irradiation with $30 \mathrm{~Gy}$ to the kidney area because of a Grawitz tumor developed ET and was treated over 7 years with hydroxyurea, $1-2 \mathrm{~g}$ daily. Because of a persistent anemia, a bone marrow aspirate was taken in 1989 , and this revealed a hypercellular marrow, with marked dyserythropoiesis, dysgranulopoiesis, and $17 \%$ myeloblastic cells. Refractory anemia with excess of blasts was diagnosed according to the myelodysplastic syndromes classification of the FAB Cooperative Group [4]. Three months later, her WBC rose to $41 \times 10^{9} /$ liter with $74 \%$ blast cells in the marrow. Acute myeloid leukemia could be confirmed. Cytogenetic examination showed no chromosomal abnormalities.

In this case, either the natural course of the disease or the hydroxyurea may be held responsible for the leukemic transformation. Our patient was never treated with alky- lating agents. She was irradiated 21 years before the onset of leukemia. Leukemias induced by irradiation have a high percentage of chromosomal abnormalities. Our patient had no cytogenetic abnormalities. The frequency of leukemic transformation in untreated patients with ET is not known. Only long-term follow-up will establish whether hydroxyurea has less leukemogenic potential than alkylating agents and ${ }^{32} \mathrm{P}$ in patients with $\mathrm{ET}$.

\section{P.J. van den Anker-Lugtenburg W. Sizoo Department of Hematology Dr. Daniel den Hoed Cancer Center Groene Hilledijk 3013075 EA Rotterdam The Netherlands}

\section{REFERENCES}

1. Toh BT, Gregory SA, Knospe WH: Acute leukemia following treatment of polycythemia vera and essential thrombocythemia with uracil mustard. Am J Hematol 28:58, 1988.

2. Sedlacek SM, Curtis JL, Weintraub J, Levin J: Essential thrombocythemia and leukemic transformation. Medicin 65:6, 1986.

3. Gris JC, Schved JF, Arnaud A, Chauvet C: Letter to the editor: Myelodysplastic syndrome and secondary acute leukemia after treatment of essential thrombocythemia with melphalen. Am J Hematol 30:47; 1989.

4. Bennet JM, Catovsky D, Daniel MT, Flandrin G, Galton DAG, Gralnick HR, Sultan CL: Proposals for the classification of the myelodysplastic syndromes. Br J Haematol 51:189, 1982. 